\title{
Evaluation of lateral atlantodental interval asymmetry in the pediatric age group: normative values
}

\author{
Stephen K. Mendenhall, MD, Andrew Huh, BA, Janit Pandya, BS, Vincent Alentado, MD, \\ Karl Balsara, MD, Chang Ho, MD, and Andrew Jea, MD, MHA
}

Section of Pediatric Neurosurgery, Riley Hospital for Children, Department of Neurological Surgery, Indiana University School of
Medicine, and Goodman Campbell Brain and Spine, Indianapolis, Indiana

OBJECTIVE The revelation of normative radiographic measurements for the developing pediatric spine is incomplete. The purpose of this analysis was to determine the normal range of asymmetry of the lateral atlantodental interval (LADI) and define age- and sex-related differences.

METHODS A total of 3072 children aged 0-18 years who underwent CT scanning of the cervical spine were identified at Riley Hospital for Children between 2005 and 2017. Patients were stratified by sex and age (in years) into 36 cohorts. Following this stratification, patients within each group were randomly selected for inclusion until 15 patients in each group had been measured (quota sampling). A total of 540 patients were included for study. Right and left linear measurements were performed in the CT axial plane at the C-1 midlateral mass level.

RESULTS The overall mean difference between the right and left LADI was $0.09 \pm 1.23 \mathrm{~mm}$ (range -6.05 to $4.87 \mathrm{~mm}$ ). The magnitude of this asymmetry remained statistically insignificant across age groups $(p=0.278)$ and $\operatorname{sex}(p=0.889)$. The intraclass correlation coefficient was 0.805 (95\% Cl 0.779-0.829).

CONCLUSIONS Asymmetry of the LADI is not unusual in asymptomatic children. There is no appreciable difference in magnitude of this asymmetry across age ranges and sex. Measurement of LADI asymmetry shows "good" reliability and is easy to perform. Pediatric neurosurgeons, emergency department physicians, and radiologists should be aware of normative values of asymmetry when interpreting CT scans of the cervical spine. This may prevent unnecessary further workup with dynamic CT or MRI.

https://thejns.org/doi/abs/10.3171/2018.2.PEDS17694

KEYWORDS trauma; pediatric cervical spine; lateral atlantodental interval; CT morphometric study; odontoid lateral mass interval; asymmetry

$\mathrm{W}$ ITH its widespread availability and use, operator independence, quick through-put, and high resolution, CT is often used in the initial evaluation of the pediatric cervical spine after trauma. ${ }^{15}$ Asymmetry of the lateral atlantodental interval (LADI) has been reported in healthy adult and pediatric patient populations with or without a history of trauma, both on plain radiographs and CT scans. . $^{2,3,5,9-13,17,24}$

However, asymmetry of LADI may also rarely indicate ligamentous injury or atlantoaxial rotatory subluxation, which, if present, could lead to catastrophic sequelae, ${ }^{18,19,22}$ a diagnostic dilemma (normal variant vs ligamentous injury). Although low yield, this leads pediatric providers to investigate further with more intensive and costly imaging studies, such as dynamic CT scanning or MRI, to exclude C1-2 ligamentous injury. ${ }^{9}$

Few previous authors have provided normative data on the developing cervical spine of a large series of asymptomatic children, and there have been no attempts to correlate these values with age and sex. Therefore, the purpose of our study was to analyze the range and magnitude of asymmetry of the LADI in a large group of asymptomat-

ABBREVIATIONS ICC = intraclass correlation coefficient; $L A D I=$ lateral atlantodental interval.

SUBMITTED December 8, 2017. ACCEPTED February 19, 2018.

INCLUDE WHEN CITING Published online May 18, 2018; DOI: 10.3171/2018.2.PEDS17694. 
ic children, as determined by routine $\mathrm{CT}$ of the cervical spine, and to document the effects of age and sex.

\section{Methods \\ Patient Population}

This study was approved by the Indiana University School of Medicine institutional review board. Patients selected for this cross-sectional study ranged in age from 0 to 18 years between 2005 and 2017 at the time of CT scanning. Each child underwent CT of the cervical spine without contrast at Riley Hospital for Children, a part of the Indiana University Health System. All eligible patients had axial images in 1- to 2.5-mm intervals from the skull base to the inferior aspect of C-2, or even more caudal. CT scans were read by board-certified pediatric radiologists within the Indiana University Health System. Only those patients with normal findings on CT scans were included for analysis. Findings on a CT scan were considered normal if there was no evidence of congenital spine abnormality, prior spine surgery, or traumatic spine injury. In addition, we reviewed the electronic medical records of these patients to confirm that there was no evidence of delayed or missed cervical spine injury on subsequent follow-up in the clinic or readmission to the hospital. Patients with inadequate resolution of the images or unsatisfactory visualization of the pediatric upper cervical spine were excluded.

We identified 3072 children who underwent cervical CT evaluation at Riley Children's Hospital between 2005 and 2017. Patients were separated by age (in years) and sex into 36 groups. The group with the most number of patients comprised the 0 - to 1-year-old boys/girls $(\mathrm{n}=274)$, and the smallest group of patients comprised the 17- to 18-yearold boys/girls $(\mathrm{n}=87)$. Using quota sampling, patients within each group were randomly selected for inclusion until 15 patients in the group had been selected, with chart review demonstrating normal CT imaging findings with- out delayed cervical instability on clinic follow-up. Quota sampling was performed on 1041 patients to fill each age group. Hence, 540 patients were included in the study.

\section{Lateral ADI Measurements}

CT scans were obtained using 16- to 64-section machines (Philips) with section widths ranging from 1 to $2.5 \mathrm{~mm}$. Measurements were performed using a PACS (picture archiving and communication system) workstation (Synapse). All measurements were performed by one author (S.K.M.) and were verified by two other authors (A.H. and J.P.) to eliminate the possibility of interobserver variability.

Each individual right and left LADI was measured in the axial plane at the C-1 midlateral mass level (Fig. 1). LADI asymmetry was calculated by subtracting the value of the left interspace from the right interspace. The values were noted in absolute and real numbers to determine the magnitude and directionality of the asymmetry.

\section{Statistical Analysis}

Means and standard deviations were calculated for each of the LADI measurements in each of the 36 groups. The Student t-test was used to test for univariate differences between sexes. One-way ANOVA was used to test for significant differences across age groups. Intraclass correlation coefficient (ICC) estimates and their 95\% confidence intervals were calculated based on a single-rater, absolute-agreement, two-way random-effects model. All statistical analysis was performed using IBM SPSS (version 24.0, IBM Corp.).

\section{Results}

\section{Patient Population}

Most patients included in our study underwent cervical CT evaluation as part of trauma evaluation $(n=511)$.
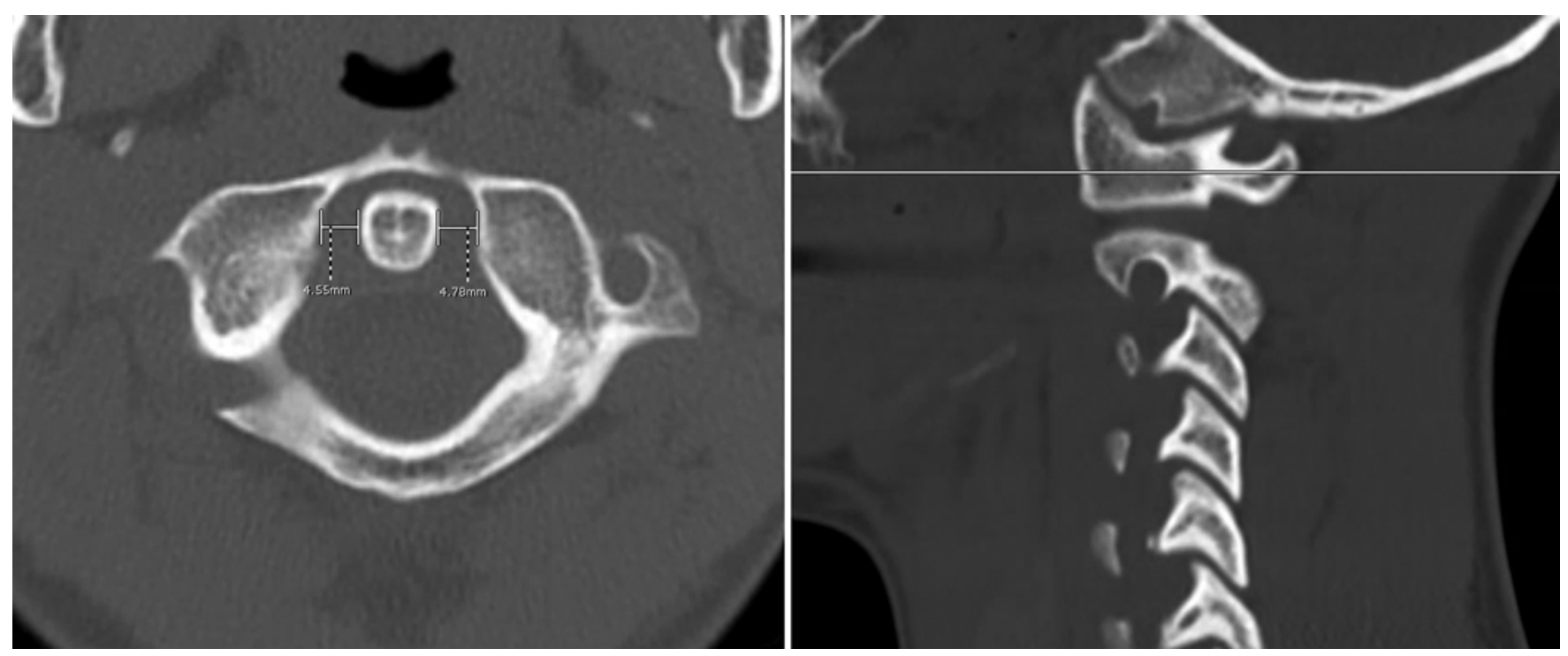

FIG. 1. Axial CT section (left) at the craniocervical junction showing LADI measurements at the C-1 midlateral mass level, which are confirmed on the sagittal CT section (right). 
TABLE 1. Measurement of asymmetry of the LADI by age in boys

\begin{tabular}{|c|c|c|c|c|c|c|}
\hline \multirow{2}{*}{$\begin{array}{l}\text { Age } \\
\text { (yrs) }\end{array}$} & \multicolumn{2}{|c|}{ Left LADI } & \multicolumn{2}{|c|}{ Right LADI } & \multicolumn{2}{|c|}{ Asymmetry of LADI } \\
\hline & Mean & SD & Mean & $\mathrm{SD}$ & Mean & SD \\
\hline 0 & 4.54 & 1.09 & 4.93 & 0.79 & 0.39 & 0.71 \\
\hline 1 & 5.90 & 1.09 & 6.12 & 0.82 & 0.22 & 1.14 \\
\hline 2 & 6.30 & 0.94 & 5.94 & 0.94 & -0.36 & 0.82 \\
\hline 3 & 6.17 & 2.13 & 5.69 & 1.13 & -0.48 & 1.80 \\
\hline 4 & 4.92 & 1.29 & 5.73 & 1.65 & 0.81 & 0.84 \\
\hline 5 & 4.59 & 0.85 & 4.92 & 0.99 & 0.30 & 0.80 \\
\hline 6 & 4.70 & 1.04 & 4.65 & 0.83 & -0.05 & 1.35 \\
\hline 7 & 4.91 & 1.29 & 4.65 & 0.97 & -0.26 & 1.38 \\
\hline 8 & 4.85 & 1.03 & 5.20 & 1.33 & 0.35 & 1.59 \\
\hline 9 & 4.38 & 1.12 & 4.52 & 1.19 & 0.13 & 1.51 \\
\hline 10 & 4.49 & 0.73 & 4.53 & 1.02 & 0.05 & 1.36 \\
\hline 11 & 4.04 & 0.84 & 4.97 & 0.67 & 0.94 & 1.23 \\
\hline 12 & 4.12 & 0.96 & 4.55 & 0.88 & 0.40 & 1.22 \\
\hline 13 & 4.63 & 0.81 & 4.24 & 0.67 & -0.39 & 1.07 \\
\hline 14 & 3.97 & 1.10 & 3.83 & 0.97 & -0.13 & 1.54 \\
\hline 15 & 3.85 & 0.71 & 3.60 & 0.68 & -0.25 & 0.93 \\
\hline 16 & 3.54 & 0.78 & 3.27 & 0.63 & -0.27 & 0.91 \\
\hline 17 & 3.64 & 0.93 & 3.71 & 0.74 & 0.07 & 1.17 \\
\hline
\end{tabular}

During quota sampling, 501 patients $(48 \%)$ were excluded upon further review for the following reasons: prior cervical fusion, prior cervical decompression, history of scoliosis, cervical spine fracture, and congenital spine anomalies. No patients were excluded for delayed cervical spine instability.

\section{LADI}

The mean LADI for boys was $4.68 \mathrm{~mm}$ (range 2.29$8.58 \mathrm{~mm}$; Table 1), and the mean LADI for girls was 4.23 $\mathrm{mm}$ (range 2.08-8.20 mm; Table 2). The LADI values for boys were significantly greater than for girls $(p<0.001)$. For both boys and girls, there was no significant difference between the right and left LADI $(p=0.282$ and $p=0.186$, respectively). The mean difference between the right and left LADI was $0.09 \mathrm{~mm}$ (range -6.05 to $4.87 \mathrm{~mm}$ ). There was no significant difference in the asymmetry of LADI across sexes $(p=0.889)$, and there was no significant difference for magnitude of asymmetry of LADI across ages $(\mathrm{p}=0.278)$. The ICC was 0.805 (95\% CI 0.779-0.829).

\section{Discussion}

In this large study of asymptomatic children, we found asymmetry of the LADI to be common on CT scans of the cervical spine. The overall mean for LADI asymmetry was $0.09 \pm 1.23 \mathrm{~mm}$ (range -6.05 to $4.87 \mathrm{~mm}$ ). Our results are consistent with those of CT-based LADI asymmetry reported by Borders et al. ${ }^{3}$ and Eran et al. ${ }^{9}(1.38 \pm 1.26 \mathrm{~mm}$ and $1.4 \pm 0.7 \mathrm{~mm}$, respectively), confirming the validity of our data.

The dilemma concerning whether additional workup is needed for a child with LADI asymmetry is encountered frequently in busy emergency departments and trauma
TABLE 2. Measurement of asymmetry of the LADI by age in girls

\begin{tabular}{|c|c|c|c|c|c|c|}
\hline \multirow{2}{*}{$\begin{array}{l}\text { Age } \\
\text { (yrs) }\end{array}$} & \multicolumn{2}{|c|}{ Left LADI } & \multicolumn{2}{|c|}{ Right LADI } & \multicolumn{2}{|c|}{ Asymmetry of LADI } \\
\hline & Mean & SD & Mean & SD & Mean & $\mathrm{SD}$ \\
\hline 0 & 4.67 & 1.09 & 4.93 & 0.79 & 0.39 & 0.71 \\
\hline 1 & 5.42 & 0.89 & 5.52 & 1.06 & 0.10 & 0.82 \\
\hline 2 & 5.89 & 1.56 & 5.79 & 1.02 & -0.10 & 1.24 \\
\hline 3 & 4.85 & 1.07 & 5.08 & 1.10 & 0.23 & 1.09 \\
\hline 4 & 4.51 & 0.93 & 4.46 & 1.08 & -0.06 & 1.51 \\
\hline 5 & 4.30 & 0.65 & 4.59 & 0.79 & 0.28 & 0.69 \\
\hline 6 & 4.25 & 0.86 & 4.20 & 0.91 & -0.06 & 1.09 \\
\hline 7 & 4.48 & 0.99 & 4.62 & 0.73 & 0.14 & 1.30 \\
\hline 8 & 4.01 & 0.52 & 4.74 & 0.81 & 0.73 & 1.08 \\
\hline 9 & 3.71 & 0.57 & 3.91 & 0.64 & 0.20 & 0.83 \\
\hline 10 & 3.89 & 0.77 & 4.26 & 0.64 & 0.37 & 1.07 \\
\hline 11 & 3.72 & 0.69 & 3.61 & 0.67 & -0.11 & 1.00 \\
\hline 12 & 3.59 & 1.00 & 3.80 & 0.92 & 0.21 & 1.23 \\
\hline 13 & 3.67 & 0.95 & 4.30 & 1.05 & 0.63 & 1.74 \\
\hline 14 & 3.67 & 0.89 & 3.32 & 0.71 & -0.34 & 1.03 \\
\hline 15 & 3.78 & 0.82 & 3.55 & 0.88 & -0.23 & 0.95 \\
\hline 16 & 3.44 & 0.79 & 3.35 & 0.74 & -0.09 & 1.34 \\
\hline 17 & 3.49 & 0.78 & 3.37 & 0.92 & -0.12 & 1.08 \\
\hline
\end{tabular}

centers. ${ }^{9}$ Mounting evidence seems to suggest that LADI asymmetry can be a normal variant in adults ${ }^{2,5,9,11-13,17,24}$ and children, ${ }^{3,9}$ or it can be related to head positioning. ${ }^{9}$ On the contrary, asymmetry of LADI can also suggest ligamentous cervical spine injury, which, if left undiagnosed or untreated, may lead to severe and catastrophic consequences. ${ }^{9,18,19,22}$ It is therefore important to establish normative values for LADI asymmetry. CT morphometric studies of the cervical spine are more complex in children because of its dynamic and growing nature..$^{1,4,6,8,20,21}$ It is not sufficient to simply establish a range of normal values; these normal values must be analyzed and stratified by age ranges. ${ }^{14,23}$ In a small series of 56 "noninjured" children, Eran et al. ${ }^{9}$ did not examine the effect of age or sex on LADI asymmetry normative values.

In another small series of 138 children, Borders et al. ${ }^{3}$ found that mean LADI asymmetry was not significantly different among 3 broad age groups: 0- to 11-month age group, 1- to 6-year age group, and 7- to 18-year age group. These results are consistent with the results of our study, which relied on more refined age group examination. In addition, however, we demonstrated that there were no differences in magnitude of asymmetry between boys and girls.

LADI asymmetry is a useful and convenient CT measurement as it seems to remain constant throughout childhood development, regardless of sex. Based on ICC analysis, measurement of LADI asymmetry shows good reliability and is easy to perform. When interpreting ICC calculations, values less than 0.5 are indicative of poor reliability, values between 0.5 and 0.75 indicate moderate reliability, values between 0.75 and 0.9 indicate good reliability, and values greater than 0.9 indicate excellent reliability. ${ }^{16}$ Our study, and the work of others, ${ }^{3,9}$ helps to 
establish a range of normal for LADI asymmetry. LADI asymmetry outside this range may require further workup with dynamic CT or MRI. Unfortunately, it is unknown whether LADI asymmetry within the range of normal needs further workup. Eran et al. ${ }^{9}$ suggested that LADI asymmetry in the absence of cervical tenderness and with a normal ADI $(<2.6 \mathrm{~mm})$ is likely due to head positioning and should not be further investigated; however, as previously mentioned, their study was significantly limited by the small number of patients enrolled.

\section{Limitations}

One of the most significant limitations of our study is that we do not practice true random sampling; random sampling in any study (where all individuals in a population have an equal chance of being selected) is difficult to achieve. Rather, we utilize nonprobability sampling. There are different types of nonprobability sampling: convenience sampling, consecutive sampling, and quota sampling. The specific method used in this study is quota sampling (a nonprobability sampling technique wherein the researcher ensures equal or proportionate representation of patients depending on which trait is considered as basis of the quota e.g., target 15 patients per group).

The disadvantage of the nonprobability sampling method is that an unknown proportion of the entire population was not sampled. This entails that the sample may or may not represent the entire population accurately. Therefore, the results of our research cannot be used in generalizations pertaining to the entire population. Furthermore, because we are based in the Midwest, our results may not be applicable to other geographic regions.

Another limitation of this study is that many patients were immobilized with a rigid cervical collar during CT scanning according to Riley Children's Hospital Emergency Medical Service and/or emergency department protocol. While the effect that rigid cervical collar immobilization has on normal radiographic spine parameters is unknown, we believe that it is minimal in our study, especially since all included patients demonstrated no delayed cervical spine injury on serial clinical follow-up.

An additional limitation of this study is excluding ligamentous injury in "normal" patients without MRI. However, other studies have established the safety and efficacy of utilizing CT for clearing the cervical spine. ${ }^{7}$ Besides, we confirmed clearance of the cervical spine through review of the electronic medical record and follow-up visits.

Finally, it would be interesting to compare LADI asymmetry measurements in patients with known injury, such as atlantoaxial rotatory subluxation, to the results of this study to determine the overlap with the normal values established by this study. This will be the subject of future multiinstitutional investigations.

\section{Conclusions}

We found the mean asymmetry between right and left LADI to be $0.09 \pm 1.23 \mathrm{~mm}$ (range -6.05 to $4.87 \mathrm{~mm}$ ). The magnitude of asymmetry is independent of age and sex. Measurement of LADI asymmetry shows good reliability and is easy to perform. We confidently and safely state that a value outside of this range of normal deserves further workup and clinical correlation to determine if there is ligamentous cervical spine injury. However, we are unable to draw definitive conclusions about a value within the normal range without also analyzing a cohort of children injured at the level of C1-2.

\section{References}

1. Al-Shamy G, Cherian J, Mata JA, Patel AJ, Hwang SW, Jea A: Computed tomography morphometric analysis for lateral mass screw placement in the pediatric subaxial cervical spine. J Neurosurg Spine 17:390-396, 2012

2. Billmann F, Bokor-Billmann T, Burnett C, Kiffner E: Occurrence and significance of odontoid lateral mass interspace asymmetry in trauma patients. World J Surg 37:1988-1995, 2013

3. Borders HL, Junewick JJ, Sherwood JM, Macke MR: Pediatric lateral atlantodental interval: how much asymmetry is normal? J Comput Assist Tomogr 35:557-559, 2011

4. Chamoun RB, Whitehead WE, Curry DJ, Luerssen TG, Jea A: Computed tomography morphometric analysis for C-1 lateral mass screw placement in children. Clinical article. J Neurosurg Pediatr 3:20-23, 2009

5. Chen Y, Zhuang Z, Qi W, Yang H, Chen Z, Wang X, et al: A three-dimensional study of the atlantodental interval in a normal Chinese population using reformatted computed tomography. Surg Radiol Anat 33:801-806, 2011

6. Chern JJ, Chamoun RB, Whitehead WE, Curry DJ, Luerssen TG, Jea A: Computed tomography morphometric analysis for axial and subaxial translaminar screw placement in the pediatric cervical spine. J Neurosurg Pediatr 3:121-128, 2009

7. Chew BG, Swartz C, Quigley MR, Altman DT, Daffner RH, Wilberger JE: Cervical spine clearance in the traumatically injured patient: is multidetector CT scanning sufficient alone? Clinical article. J Neurosurg Spine 19:576-581, 2013

8. Engelberg RB, Roguski M, Riesenburger RI, Do-Dai D, Jea A, Hwang SW: Morphometric analysis of lumbar pedicles in patients with spinal dysraphism. Pediatr Neurosurg 50:1-6, 2015

9. Eran A, Yousem DM, Izbudak I: Asymmetry of the odontoid lateral mass interval in pediatric trauma CT: do we need to investigate further? AJNR Am J Neuroradiol 37:176-179, 2016

10. Fielding JW, Hawkins RJ: Atlanto-axial rotatory fixation. (Fixed rotatory subluxation of the atlanto-axial joint). J Bone Joint Surg Am 59:37-44, 1977

11. Harty JA, Lenehan B, O'Rourke SK: Odontoid lateral mass asymmetry: do we over-investigate? Emerg Med J 22:625627,2005

12. Hohl M, Baker HR: The atlanto-axial joint: roentgenographic and anatomical study of normal and abnormal motion. J Bone Joint Surg Am 46:1739-1752, 1964

13. Iannacone WM, DeLong WG Jr, Born CT, Bednar JM, Ross SE: Dynamic computerized tomography of the occiput-atlasaxis complex in trauma patients with odontoid lateral mass asymmetry. J Trauma 30:1501-1505, 1990

14. Johnson KT, Al-Holou WN, Anderson RC, Wilson TJ, Karnati T, Ibrahim M, et al: Morphometric analysis of the developing pediatric cervical spine. J Neurosurg Pediatr 18:377-389, 2016

15. Keenan HT, Hollingshead MC, Chung CJ, Ziglar MK: Using CT of the cervical spine for early evaluation of pediatric patients with head trauma. AJR Am J Roentgenol 177:14051409,2001

16. Koo TK, Li MY: A guideline of selecting and reporting Intraclass correlation coefficients for reliability research. J Chiropr Med 15:155-163, 2016 
17. Lee S, Joyce S, Seeger J: Asymmetry of the odontoid-lateral mass interspaces: a radiographic finding of questionable clinical significance. Ann Emerg Med 15:1173-1176, 1986

18. Lustrin ES, Karakas SP, Ortiz AO, Cinnamon J, Castillo M, Vaheesan K, et al: Pediatric cervical spine: normal anatomy, variants, and trauma. Radiographics 23:539-560, 2003

19. Mirvis SE: How much lateral atlantodental interval asymmetry and atlantoaxial lateral mass asymmetry is acceptable on an open-mouth odontoid radiograph, and when is additional investigation necessary? AJR Am J Roentgenol 170:11061107, 1998

20. Patel AJ, Cherian J, Fulkerson DH, Fox BD, Chern JJ, Whitehead WE, et al: Computed tomography morphometric analysis for translaminar screw fixation in the upper thoracic spine of the pediatric population. J Neurosurg Pediatr 7:383-388, 2011

21. Patel AJ, Gressot LV, Cherian J, Desai SK, Jea A: Far lateral paracondylar versus transcondylar approach in the pediatric age group: CT morphometric analysis. J Clin Neurosci 21:2194-2200, 2014

22. Roche C, Carty H: Spinal trauma in children. Pediatr Radiol 31:677-700, 2001

23. Vachhrajani S, Sen AN, Satyan K, Kulkarni AV, Birchansky $\mathrm{SB}$, Jea A: Estimation of normal computed tomography measurements for the upper cervical spine in the pediatric age group. J Neurosurg Pediatr 14:425-433, 2014

24. Wolansky LJ, Rajaraman V, Seo C, Patel N, Kazmi K, Dod- dakashi S, et al: The lateral atlanto-dens interval: normal range of asymmetry. Emerg Radiol 6:290-293, 1999

\section{Disclosures}

The authors report no conflict of interest concerning the materials or methods used in this study or the findings specified in this paper.

\section{Author Contributions}

Conception and design: all authors. Acquisition of data: all authors. Analysis and interpretation of data: Jea, Mendenhall, Alentado, Balsara, Ho. Drafting the article: Jea, Mendenhall, Alentado, Balsara, Ho. Critically revising the article: Jea, Mendenhall. Reviewed submitted version of manuscript: all authors. Approved the final version of the manuscript on behalf of all authors: Jea. Statistical analysis: Jea, Mendenhall, Huh, Pandya, Alentado, Balsara, Ho. Administrative/technical/material support: all authors. Study supervision: Jea, Mendenhall, Alentado, Balsara, Ho.

\section{Correspondence}

Andrew Jea: Riley Hospital for Children, Indianapolis, IN. ajea@ goodmancampbell.com. 